\title{
The Preventive Effects of two Different Doses of Dexmedetomidine on Shivering in Cesarean Section under Spinal Anesthesia
}

\author{
BEHZAD NAZEMROAYA*1, SAMIRA HEYDARI ${ }^{2}$ \\ ${ }^{1}$ Assistant Professor, Anesthesiology and Critical Care Research Center, Isfahan University of Medical Sciences, Isfahan, Iran. \\ ${ }^{2}$ School of Medicine, Isfahan University of Medical Sciences, Isfahan, Iran.
}

\begin{abstract}
Introduction: One of the side effects caused by spinal anesthesia is seizures of impaired body temperature regulation, which in addition to causing concern for the mother, can lead to problems such as cardiovascular and respiratory disorders. This has led to the choice of the appropriate drug to reduce shivering, with the least neonatal and maternal side effects in cesarean section. The main purpose of this study was to compare the prophylactic effect of intravenous dexmedetomidine at two different doses for cesarean section induced shivering under spinal anesthesia.

Methods: This article is a double blind randomized clinical trial study performed in Isfahan University of Medical Sciences (Alzahra and Shahid Beheshti). The target population of the study was pregnant women with indication of cesarean section. In this study 60 pregnant women were divided into three groups. In the first group patients were injected with $2.5 \mathrm{mg} / \mathrm{kg}$ dexmedetomidine, in the second group patients with $5 \mathrm{mg} / \mathrm{kg}$ dexmedetomidine and in the third group with similar volume, normal saline was injected and the shivering intensity in patients with the use of Grassi and Mahajan criteria was evaluated. Finally, the collected data were analyzed using SPSS software and Kruskal-Wallis One-Way ANOVA tests.

Results: According to the statistical analysis of the data, after cesarean section with spinal anesthesia, shivering intensity in the $5 \mathrm{mg} / \mathrm{kg}$ dexmedetomidine group was lower than in the $2.5 \mathrm{mg}$ group and less than the control group. Normal saline was given as prophylaxis.

Conclusion: Intravenous dexmedetomidine, especially at a dose of $5 \mu \mathrm{g} / \mathrm{kg}$, has a significant effect on reducing postoperative shivering by cesarean section with spinal anesthesia.
\end{abstract}

Keywords: Dexmedetomidine, Shivering, Cesarean section, Spinal anesthesia

\section{INTRODUCTION}

Shivering is an involuntary oscillation of muscles happening physiologically in response to hypothermia (1). Prolonged disturbance of the autonomic control center of the cold environment of the surgery room and the prescribed cold liquids decreases body temperature and leads to shivering. Postoperative shivering is of the common complications of spinal anesthesia with different prevalence in various studies depending on age, gender, type of surgery, and medications used. Shivering is an unpleasant feeling for the patient that could lead to anxiety (2). It causes tension and pressure at the wound site and aggravates the pain. It speeds up the body's metabolism and thus oxygen consumption in the body by up to 400 and sometimes even up to $600 \%$, which results in arterial hypoxia, increased production of carbon dioxide and lactic acid, and increased circulating catecholamines in circulation. Spinal anesthesia (SA) is widely used for elective and emergency cesarean sections. SA brings about adequate anesthesia and analgesia compared to the common risks of general anesthesia (3). In SA, the prevalence of postoperative shivering has been reported at $0-70 \%$ range. Regional anesthesia intensifies vasoconstriction and causes shivering above the surface of the block because of a decrease of 0 and a half degrees Celsius on the threshold of body temperature regulation (4). This decrease is made proportional to the age, the level of sensory block, and the number of blocked segments. The decreased sympathetic tone during Spanish anesthesia causes hypotension in the patient (3).
According to a study by Hui et al., the prevalence of postoperative shivering increases in pregnant women under cesarean section with SA (3).

Shivering is of the most prevalent complications after any type of surgery with many drugs such as clonidine, butorphanol, tramadol, pethidine, ketamine, dexamethasone, midazolam, propofol, and many narcotic and non-narcotic compounds used to treat and pvent it (4).

Dexmedetomidine is an alpha-2 agonist receptor inhibiting the release of norepinephrine by the action of $\mathrm{g}$ proteins through acting on these receptors in the central nervous system, thus inducing hypnotic and analgesic effects in a dose-dependent way that leads to sedation and anesthesia without the effects of respiratory failure (5). Dexmedetomidine action mechanism in inhibiting shivering is complex. Unlike other patients, those receiving dexmedetomidine wake up easily without showing signs of irritability. The studies on this indicate that dexmedetomidine injection could be useful in procedures that need heart rate and blood pressure evaluations (6).

Alpha-2 adrenergic receptors, abundant in the hypothalamus, seem to mediate heat regulation inhibition. Many studies have shown that dexmedetomidine increases the temperature range by stimulating alpha 2 adrenergic central receptors without stimulating thermoregulatory defense. Thus, it reduces the heat stimulation threshold leading to shivering. The anticonvulsant effect of intrathecal dexmedetomidine could be because of a decrease in the shivering threshold $(3,4)$.

Many studies have indicated that intravenous dexmedetomidine (IV) prophylaxis injection of 0.5 or 1 $\mathrm{mg} / \mathrm{kg}$ body weight reduces postoperative shivering $(3,4)$. 
Numerous studies have indicated that to prolong the analgesic period in upper and lower extremities and cesarean section surgeries, dexmedetomidine is an effective adjuvant in intrathecal local anesthesia (7).

Nonetheless, a clinical trial meta-analysis recently indicated that intravenous dexmedetomidine injection did not work optimally in preventing shivering because of its severe complications. Moreover, the studies dealing with the effect of intravenous (IV) dexmedetomidine on cesarean section involve specific case-control studies like a pregnant woman with primary pulmonary hypertension or another case with spinal muscular atrophy (3).

Among the cases recommended to prevent postoperative shivering following spinal anesthesia are magnesium sulfate in Alipour et al. (8), ketamine in two various doses in Jabal Ameli et al. (9), pethidine compared to ketamine in Pazouki et al. (10), Tramadol in Sahmalini et al. (11), the effect of dexmedetomidine in the femoral block on the rate of hemodynamic changes during shaft fracture surgery in Memari et al. (3), the effect of dexmedetomidine on hemodynamic changes, duration of seizures and recovery in patients undergoing electroconvulsive therapy (ECT) in Safari et al. (12). and the effect of intrathecal use of dexmedetomidine in reducing the incidence and severity of shivering in pregnant women undergoing cesarean section in Naseri et al. (13).

Despite the comparative study of various medicines in preventing shivering after cesarean section with SA (3), the effect of various doses of dexmedetomidine on shivering after the cesarean section was not examined, and because of its significance, the present study has been conducted for comparing the effect of $2.5 \mu \mathrm{g}$ and $5 \mu \mathrm{g}$ of Dexmedetomidine IV in the prevention of shivering after spinal anesthesia in pregnant women undergoing cesarean section with spinal anesthesia in Alzahra and Shahid Beheshti hospitals in Isfahan (3).

\section{METHOD}

The present ahead was a double-blind randomized clinical trial with a control group carried out in the educational and medical centers of Isfahan University of Medical Sciences in 2019. Sixty pregnant women with cesarean section indication entered the study after obtaining the patient's consent to participate in the study with the following conditions: pregnant women in 18-45 years age range with physical condition 1 and 2 candidates for cesarean section.

Moreover, those with a history of allergies to alphaadrenergic drugs, liver disease, a history of bradycardia, grade 2 or 3 AV block, vascular problems, low blood pressure, type 2 diabetes, hypovolemia, taking vasodilators or the medicines altering core body temperature, drug abuse, hemorrhage during the study in need of a transfusion, becoming allergic, or anesthesia technique changed for them were excluded from the study.

Then the sample size needed for the study was determined using the following formula as a result of which, at least 20 people were placed in each group.

$N=\frac{\left(Z_{1+} Z_{2}\right)^{2}\left(2 S^{2}\right)}{\mathrm{D}^{2}}$

After approving the project and obtaining permission from the Medical Ethics Committee of Isfahan University of
Medical Sciences, 60 pregnant women were selected as candidates for cesarean section with the inclusion criteria. After obtaining their consent to participate in the study and the written consent, they were divided into three groups of 25 people by randomization using Random Allocation software. The study was carried out as a double-blind study and the patient and the physician conducting the project were unaware of the type of injectable drug to the patient. Evaluating shivering intensity in patients was done using Grassi and Mahajan criteria.

All the patients received a $7 \mathrm{ml} / \mathrm{kg}$ lactate ringer half an hour before operation without receiving prodrug and standard care and monitoring including a pulse oximeter, ECG, and sphygmomanometer were performed for the patient.

SA was carried out in a sitting position using $2.5 \mathrm{ml}$ of half a percent hyper-narrow bupivacaine $(10 \mathrm{mg})$ in the $\mathrm{L} 3$ L4 vertebral space with a 20-gauge needle. After fetal removal and umbilical cord clamp, the patients in the first group received $02.5 \mathrm{mg} / \mathrm{kg}$ dexmedetomidine. The patients in the second group received $5 \mathrm{mg} / \mathrm{kg}$ dexmedetomidine, and the third group received a similar volume of normal saline. The maximum level of sensory block was evaluated by the pin-prick method using a needle. The volume of the drugs was $5 \mathrm{ml}$ in volume, and after the fetus was removed and the umbilical cord clamped, it was injected intravenously using a $100 \mathrm{cc}$ microset of $5 \%$ water dextrose within 10 minutes. The data was collected by another person who was not injecting the medicine. Measuring the patients' body temperature was done by the sensors connected to the patient's body and on the other hand to the monitor.

Moreover, central body temperature was measured by a sensor connected to the tympanic membrane and connected to the monitor on the other side.

Systolic and diastolic and mean arterial blood pressure, heart rate, oxygen saturation before spinal anesthesia and at 5, 15, and 30 minutes after spinal anesthesia, as well as central and ambient temperature 3 minutes before spinal anesthesia and then every 15 minutes during spinal anesthesia until exit from recovery, was measured and recorded. The prevalence of shivering and the severity of shivering were examined and recorded at the same time. Moreover, the complications of this drug such as nausea, vomiting, and itching were examined and recorded.

Patient's demographic data, ASA physical condition during surgery (from the first incision to the last suture), anesthesia duration (from anesthesia to return of sensory level to two higher stages), and length of stay in recovery from entry into recovery until the patient was discharged in good general condition and after the sensation around the umbilicus returned, all patients' drug use was recorded in the data collection form.

In cases where the mother's heart rate was less than 90 during anesthesia, an atropine syringe was being prescribed, and the intervention as $10 \mathrm{mg}$ bolus ephedrine was being prescribed when the systolic blood pressure reached less than $100 \mathrm{~mm} \mathrm{Hg}$ during anesthesia. Blankets and heat lamps were used for the treatment of grades 1 and 2 shiverings and pethidine at a rate of $0.4 \mathrm{Mg} / \mathrm{kg}$ was used in grades 3 and above. The collected data was 
analyzed in SPSS 23 software, Kruskal-Wallis test, and one-way analysis of variance (one-way ANOVA) and Chisquare tests.

\section{RESULTS}

The study was carried out on 60 pregnant women candidates for cesarean section with spinal anesthesia and divided into three groups of 20 . Group A received $2.5 \mu \mathrm{g} /$ $\mathrm{kg}$ of dexmedetomidine, group B $5 \mu \mathrm{g} \mathrm{/} \mathrm{kg}$ of dexmedetomidine, and group $\mathrm{C}$ received normal saline.
They were reviewed from various angles in line with the objectives of the proposal and the following main results were obtained:

According to Table 1, the severity of shivering was lower in group $B$ than in group $A$ and less in group $A$ than in group $\mathrm{C}$ after cesarean section with spinal anesthesia. Thus, a higher dose of dexmedetomidine was more effective in preventing shivering following spinal anesthesia after cesarean section.

Table 1. Frequency distribution of shivering severity at various times in three groups

\begin{tabular}{|c|c|c|c|c|c|c|}
\hline \multicolumn{2}{|c|}{ Quantitative variable } & Frequency & Mean & $\begin{array}{l}\text { Standard } \\
\text { deviation }\end{array}$ & Min. & Max. \\
\hline \multirow{6}{*}{\begin{tabular}{l}
$\Omega$ \\
$\Omega$ \\
0 \\
\multicolumn{1}{c}{} \\
$D$ \\
$D$
\end{tabular}} & Prior to anesthesia & 20 & 0.15 & 0.36 & 0 & 1 \\
\hline & 15 minutes after anesthesia & 20 & 0.25 & 0.44 & 0 & 1 \\
\hline & Second 15 minutes after anesthesia & 20 & 0.60 & 0.88 & 0 & 3 \\
\hline & Third 15 minutes after anesthesia & 20 & 1.20 & 1.54 & 0 & 4 \\
\hline & Fourth 15 minutes after anesthesia & 20 & 0.80 & 1.28 & 0 & 4 \\
\hline & Recovery & 20 & 0.50 & 0.94 & 0 & 3 \\
\hline \multirow{6}{*}{$\begin{array}{l}\text { @) } \\
\text { O) } \\
\frac{1}{0} \\
0\end{array}$} & Prior to anesthesia & 20 & 0.10 & 0.30 & 0 & 1 \\
\hline & 15 minutes after anesthesia & 20 & 0.15 & 0.36 & 0 & 1 \\
\hline & Second 15 minutes after anesthesia & 20 & 0.3 & 0.65 & 0 & 2 \\
\hline & Third 15 minutes after anesthesia & 20 & 0.25 & 0.55 & 0 & 2 \\
\hline & Fourth 15 minutes after anesthesia & 20 & 0.30 & 0.47 & 0 & 1 \\
\hline & Recovery & 20 & 0.25 & 0.44 & 0 & 1 \\
\hline \multirow{6}{*}{$\begin{array}{l}\Omega \\
0 \\
0 \\
0 \\
0 \\
0\end{array}$} & Prior to anesthesia & 20 & 0.73 & 0.99 & 0 & 3 \\
\hline & 15 minutes after anesthesia & 20 & 0.94 & 0.07 & 0 & 3 \\
\hline & Second 15 minutes after anesthesia & 20 & 1 & 0.10 & 0 & 3 \\
\hline & Third 15 minutes after anesthesia & 20 & 2.15 & 0.50 & 0 & 4 \\
\hline & Fourth 15 minutes after anesthesia & 20 & 1.63 & 1.34 & 0 & 4 \\
\hline & Recovery & 20 & 1.36 & 1.30 & 0 & 4 \\
\hline
\end{tabular}

Table 2. Frequency distribution of central temperature at different times in three groups

\begin{tabular}{|c|c|c|c|c|c|c|}
\hline \multicolumn{2}{|c|}{ Quantitative variable } & Frequency & Mean & $\begin{array}{l}\text { Standard } \\
\text { deviation }\end{array}$ & Min. & Max. \\
\hline \multirow{6}{*}{$\begin{array}{l}\Omega \\
\Omega \\
0 \\
\frac{0}{0} \\
>\end{array}$} & Before anesthesia & 20 & 36.76 & 0.34 & 36 & 37 \\
\hline & 15 minutes after anesthesia & 20 & 36.63 & 0.53 & 35.20 & 37.10 \\
\hline & Second 15 minutes after anesthesia & 20 & 36.61 & 0.53 & 35.20 & 37.50 \\
\hline & Third 15 minutes after anesthesia & 20 & 36.76 & 0.62 & 35.40 & 38.20 \\
\hline & Fourth 15 minutes after anesthesia & 20 & 36.55 & 0.40 & 35.30 & 37 \\
\hline & Recovery & 20 & 36.63 & 0.35 & 36 & 37 \\
\hline \multirow{6}{*}{ 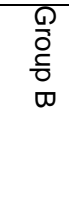 } & Prior to anesthesia & 20 & 36.99 & 0.43 & 36 & 37 \\
\hline & 15 minutes after anesthesia & 20 & 37.04 & 0.56 & 36 & 37.50 \\
\hline & Second 15 minutes after anesthesia & 20 & 37.04 & 0.53 & 36 & 37.50 \\
\hline & Third 15 minutes after anesthesia & 20 & 37.19 & 0.40 & 36 & 37.50 \\
\hline & Fourth 15 minutes after anesthesia & 20 & 37.26 & 0.27 & 36.50 & 37.70 \\
\hline & Recovery & 20 & 37.20 & 0.39 & 36 & 37.50 \\
\hline \multirow{6}{*}{ 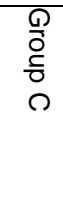 } & Prior to anesthesia & 20 & 36.55 & 0.59 & 35.60 & 37.20 \\
\hline & 15 minutes after anesthesia & 20 & 36.60 & 0.65 & 35.60 & 37.30 \\
\hline & Second 15 minutes after anesthesia & 20 & 36.65 & 0.61 & 35.60 & 37.50 \\
\hline & Third 15 minutes after anesthesia & 20 & 36.32 & 0.68 & 35 & 37.50 \\
\hline & Fourth 15 minutes after anesthesia & 20 & 36.56 & 0.52 & 35.60 & 37.40 \\
\hline & Recovery & 20 & 36.57 & 0.61 & 35.60 & 37.50 \\
\hline
\end{tabular}


Table 3. Frequency distribution of ambient temperature at various times in three groups

\begin{tabular}{|c|c|c|c|c|c|c|}
\hline \multicolumn{2}{|c|}{ Quantitative variable } & Frequency & Mean & Standard deviation & Min. & Max. \\
\hline \multirow{6}{*}{$\begin{array}{l}9 \\
0 \\
0 \\
0 \\
D \\
D\end{array}$} & Prior to anesthesia & 20 & 36.63 & 0.52 & 35 & 37.50 \\
\hline & 15 minutes after anesthesia & 20 & 36.38 & 0.51 & 35 & 37 \\
\hline & Second 15 minutes after anesthesia & 20 & 36.32 & 0.46 & 35.10 & 36.90 \\
\hline & Third 15 minutes after anesthesia & 20 & 36.34 & 0.35 & 35.60 & 37 \\
\hline & Fourth 15 minutes after anesthesia & 20 & 36.72 & 0.42 & 36.10 & 37.50 \\
\hline & Recovery & 20 & 36.60 & 0.67 & 35.20 & 38 \\
\hline \multirow{6}{*}{$\begin{array}{l}\frac{\Omega}{0} \\
\frac{0}{0} \\
0 \\
0\end{array}$} & Before anesthesia & 20 & 37.21 & 0.30 & 36.10 & 37.40 \\
\hline & 15 minutes after anesthesia & 20 & 37.06 & 0.41 & 35.70 & 37.40 \\
\hline & Second 15 minutes after anesthesia & 20 & 36.98 & 0.58 & 35.50 & 37.50 \\
\hline & Third 15 minutes after anesthesia & 20 & 36.98 & 0.53 & 35.60 & 37.40 \\
\hline & Fourth 15 minutes after anesthesia & 20 & 36.93 & 0.47 & 35.70 & 37.50 \\
\hline & Recovery & 20 & 36.96 & 0.49 & 35.80 & 37.40 \\
\hline \multirow{6}{*}{$\begin{array}{l}\text { ه } \\
\frac{0}{0} \\
\frac{1}{0} \\
\Omega\end{array}$} & Before anesthesia & 20 & 36.58 & 0.56 & 35.80 & 37.40 \\
\hline & 15 minutes after anesthesia & 20 & 36.42 & 0.48 & 35.70 & 37.40 \\
\hline & Second 15 minutes after anesthesia & 20 & 36.39 & 0.49 & 35.70 & 37.40 \\
\hline & Third 15 minutes after anesthesia & 20 & 36.33 & 0.46 & 35.70 & 37.40 \\
\hline & Fourth 15 minutes after anesthesia & 20 & 35.90 & 0.63 & 35 & 37.40 \\
\hline & Recovery & 20 & 36.01 & 0.64 & 35 & 37.10 \\
\hline
\end{tabular}

Based on Tables 4 and 5 , the level of sedation and pain intensity of the drug was true and the degree of sedation and pain relief was higher in group $B$ than group $A$ and group $\mathrm{A}$ than group $\mathrm{C}$.

Table 4. Frequency distribution of sedation levels at various times according to the three groups studied

\begin{tabular}{|c|c|c|c|c|c|c|}
\hline \multicolumn{2}{|c|}{ Quantitative variable } & Frequency & Mean & Standard deviation & Min. & Max. \\
\hline \multirow{6}{*}{$\begin{array}{l}\text { Q } \\
0 \\
\frac{1}{0} \\
D\end{array}$} & Prior to anesthesia & 20 & 4.45 & 0.68 & 4 & 6 \\
\hline & 15 minutes after anesthesia & 20 & 4.10 & 0.71 & 3 & 6 \\
\hline & Second 15 minutes after anesthesia & 20 & 3.50 & 1.00 & 1 & 5 \\
\hline & Third 15 minutes after anesthesia & 20 & 3.55 & 1.43 & 1 & 5 \\
\hline & Fourth 15 minutes after anesthesia & 20 & 3.50 & 1.31 & 1 & 6 \\
\hline & Recovery & 20 & 3.10 & 1.11 & 1 & 5 \\
\hline \multirow{6}{*}{ 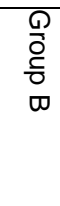 } & Prior to anesthesia & 0 & 4.15 & 0.67 & 3 & 5 \\
\hline & 15minutes after anesthesia & 20 & 3.30 & 0.80 & 2 & 4 \\
\hline & Second 15 minutes after anesthesia & 20 & 2.45 & 0.75 & 1 & 4 \\
\hline & Third 15 minutes after anesthesia & 20 & 2.45 & 0.94 & 1 & 4 \\
\hline & Fourth 15 minutes after anesthesia & 20 & 2.25 & 1.06 & 1 & 5 \\
\hline & Recovery & 20 & 2.05 & 0.94 & 1 & 4 \\
\hline \multirow{6}{*}{\begin{tabular}{l}
$\Omega$ \\
$\Omega$ \\
0 \\
\multicolumn{1}{c}{} \\
0 \\
0
\end{tabular}} & Prior to anesthesia & 20 & 4.80 & 0.83 & 3 & 6 \\
\hline & 15 minutes after anesthesia & 20 & 4.15 & 1.13 & 2 & 6 \\
\hline & Second 15 minutes after anesthesia & 20 & 3.35 & 0.93 & 2 & 5 \\
\hline & Third 15 minutes after anesthesia & 20 & 4.10 & 1.61 & 2 & 6 \\
\hline & Fourth 15 minutes after anesthesia & 20 & 3.70 & 1.45 & 1 & 6 \\
\hline & Recovery & 20 & 2.75 & 1.44 & 1 & 6 \\
\hline
\end{tabular}

Table 5. Frequency distribution of pain intensity at various times according to the three groups studied

\begin{tabular}{|c|c|c|c|c|c|c|}
\hline \multicolumn{2}{|c|}{ Quantitative variable } & Frequency & Mean & Standard deviation & Min. & Max. \\
\hline \multirow{6}{*}{$\begin{array}{l}\Omega \\
0 \\
\frac{0}{0} \\
D\end{array}$} & Prior to anesthesia & 20 & 3.65 & 2.90 & 0 & 7 \\
\hline & 15 minutes after anesthesia & 20 & 2.65 & 2.41 & 0 & 6 \\
\hline & Second 15 minutes after anesthesia & 20 & 1.70 & 1.55 & 0 & 5 \\
\hline & Third 15 minutes after anesthesia & 20 & 1.50 & 1.50 & 0 & 4 \\
\hline & Fourth 15 minutes after anesthesia & 20 & 1.30 & 1.30 & 0 & 4 \\
\hline & Recovery & 20 & 1.10 & 0.91 & 0 & 2 \\
\hline \multirow{6}{*}{\begin{tabular}{l}
$\Omega$ \\
\multicolumn{1}{c}{} \\
$\frac{1}{0}$ \\
$\infty$
\end{tabular}} & Prior to anesthesia & 20 & 2.65 & 1.59 & 0 & 5 \\
\hline & 15 minutes after anesthesia & 20 & 1.15 & 1.26 & 0 & 4 \\
\hline & Second 15 minutes after anesthesia & 20 & 0.70 & 0.92 & 0 & 3 \\
\hline & Third 15 minutes after anesthesia & 20 & 0.60 & 0.88 & 0 & 3 \\
\hline & Fourth 15 minutes after anesthesia & 20 & 0.40 & 0.82 & 0 & 3 \\
\hline & Recovery & 20 & 0.35 & 0.67 & 0 & 2 \\
\hline \multirow{6}{*}{$\begin{array}{l}0 \\
0 \\
0 \\
\frac{1}{0} \\
0\end{array}$} & Prior to anesthesia & 20 & 4.40 & 1.66 & 3 & 8 \\
\hline & 15 minutes after anesthesia & 20 & 2.90 & 1.61 & 0 & 6 \\
\hline & Second 15 minutes after anesthesia & 20 & 1.45 & 0.68 & 0 & 3 \\
\hline & Third 15 minutes after anesthesia & 20 & 1.20 & 0.52 & 0 & 2 \\
\hline & Fourth 15 minutes after anesthesia & 20 & 1.15 & 0.48 & 0 & 2 \\
\hline & Recovery & 20 & 1.25 & 0.63 & 0 & 3 \\
\hline
\end{tabular}


The complications rate was lower in group $B$ than $A$ and group $\mathrm{A}$ than $\mathrm{C}$. Finally, no significant results were obtained in comparison and review of other cases.

\section{DISCUSSION}

The shivering complication in cesarean section, particularly with spinal anesthesia, is relatively high so that in 52 to $82 \%$ of cases, it is seen that it causes discomfort to the patient, delayed communication between mother and baby, as well as disturbances in the healing process. Currently, many narcotic and non-narcotic drugs are used in hospitals to control this condition, with complications such as respiratory depression, hypotension, and nausea and vomiting. The most commonly used drug for this purpose is meperidine, which can lead to complications such as respiratory depression, nausea, vomiting, and prenatal effects on the newborn, and care should be taken in its prescription (1).

Thus, selecting the proper drug to control maternal shivering after cesarean section with SA with low complications for mother and baby is an important point and the studies carried out in this regard and drugs to improve this condition have been suggested many narcotic and non-narcotic compounds have been used in recent years (4). In an extensive study in terms of the number of people and five drugs at the same time, which was not similar to this study before and by Sajedi et al. (2003) among them, 5354 people candidates for the elective operation were examined, of whom 1767 patients (31\%) developed shivering, among whom 160 were grade 3 and 4 shivering patients randomly treated with five drugs alfentanil, fentanyl, sufentanil, pethidine, and tramadol. There were no differences between these drugs (14).

Dexmedetomidine is an alpha-2 agonist receptor that, by acting on these receptors in the central nervous system, inhibits the release of norepinephrine due to the action of $\mathrm{g}$ proteins, thereby inducing dose-dependent hypnotic and analgesic effects provide sedation and anesthesia without the effects of respiratory failure [15]. Dexmedetomidine action mechanism is complex in inhibiting shivering. Unlike other patients, the patients receiving dexmedetomidine wake up easily without any signs of irritability. The relevant studies indicate that dexmedetomidine injection could prove useful in procedures that need heart rate and blood pressure evaluations (10).

The results of Memari et al. - one of the first studies on the effects of dexmedetomidine on the prevention of shivering, entitled "The study of the effect of dexmedetomidine in a femoral block on hemodynamic changes during femoral shaft fracture surgery" - indicated that dexmedetomidine alone could lead to a gradual decrease in mean heart rate and systolic and diastolic blood pressure in patients with femoral shaft fracture (10). The results of Safari et al. - entitled the effect of dexmedetomidine on hemodynamic on the duration of seizures and recovery in patients undergoing electroconvulsive therapy (ECT) - showed that the prodrug dexmedetomidine could significantly reduce systolic pressure in the propofol group compared to the control group in three minutes. It could also reduce systolic pressure in the group receiving etomidate in 10 minutes compared to the control group. Significantly reduce. Nonetheless, the duration of recovery in the etomidate group was significantly increased compared to the control group (11).

Naseri et al. (2017) showed that intrathecal using dexmedetomidine affects reducing the incidence and severity of shivering among the pregnant women undergoing cesarean section without severe complications (13).

Several studies have shown that Dexmedetomidine IV prophylaxis injection of 0.5 or $1 \mathrm{mg} / \mathrm{kg}$ body weight reduces postoperative shivering (16). Many studies have revealed that to prolong the period of analgesia in limb surgery upper, lower and cesarean section, dexmedetomidine is an effective adjuvant in intrathecal local anesthesia (17).

Nevertheless, a clinical trial meta-analysis study by Zhang et al. revealed that intravenous injection of dexmedetomidine was not optimal because of its severe complications to prevent shivering. Furthermore, Avesta et al., studying the effect of Dexmedetomidine IV in cesarean section, included special case studies, such as a pregnant woman with primary pulmonary hypertension or another case of spinal muscular atrophy (18).

The purpose of the study was to compare the effect of two various doses of $2.5 \mu \mathrm{g}$ and $5 \mu \mathrm{g}$ on dexmedetomidine IV in preventing shivering after spinal anesthesia in pregnant women undergoing cesarean section with spinal anesthesia in Alzahra and Shahid Beheshti hospitals of Isfahan showed a better preventive effect with a higher dose of dexmedetomidine with fewer complications.

However, because of the high prevalence of this complication and the many effects it could have on mother and infant, it is essential to carry out more studies on the preventive effects of this drug or other drugs in various doses and the severity of complications.

Moreover, the preventive effects of this drug on shivering after spinal anesthesia in other important surgeries can be examined.

\section{CONCLUSION}

Based on the statistical analysis of the data obtained, the severity of shivering in the group consuming $5 \mu \mathrm{g} / \mathrm{kg}$ dexmedetomidine was less than the group consuming 2.5 $\mu \mathrm{g}$ after cesarean section with spinal anesthesia. Among them, it was less than the group consuming normal saline and thus higher doses of dexmedetomidine were more effective in preventing shivering following spinal anesthesia after cesarean section.

Acknowledgments: The present paper is the result of a professional doctoral thesis approved with 398754 number by Vice Chancellor for Research, School of Medicine, Isfahan University of Medical Sciences, and was carried out with the support of the vice-chancellor. Hence, the paper authors appreciate them for all their efforts.

\section{REFERENCES}

1. Collins S, Budds M, Raines C, Hooper V. Risk Factors for Perioperative Hypothermia: A Literature Review. Journal of PeriAnesthesia Nursing. 2019; 34(2):338-46.

2. Allen TK, Habib AS. Inadvertent perioperative hypothermia induced by spinal anesthesia for cesarean delivery might be 
more significant than we think: are we doing enough to warm our parturients? Anesthesia and analgesia. 2018; 126(1):7.

3. HONARMAND A, SAFAVI MR, MANSORIAN S. Evaluating the prophylactic effect of magnesium sulfate and combination of midazolam and ketamine for prevention of shivering during regional anaesthesia. $\mathrm{Br} \mathrm{J}$ Anaesth. 2008; 101(4):557-62.

4. Buvanendran A, McCarthy RJ, Kroin JS, Leong W, Perry P, Tuman KJ. Intrathecal magnesium prolongs fentanyl analgesia: a prospective, randomized, controlled trial. Anesthesia \& Analgesia. 2002; 95(3):661-6.

5. Panchgar V, Shetti AN, Sunitha H, Dhulkhed VK, Nadkarni A. The effectiveness of intravenous dexmedetomidine on perioperative hemodynamics, analgesic requirement, and side effects profile in patients undergoing laparoscopic surgery under general anesthesia. Anesthesia, essays and researches. 2017; 11(1):72.

6. Mahmoud M, Mason K. Dexmedetomidine: review, update, and future considerations of paediatric perioperative and periprocedural applications and limitations. British journal of anaesthesia. 2015; 115(2):171-82.

7. Ameta N, Jacob M, Hasnain S, Ramesh G. Comparison of prophylactic use of ketamine, tramadol, and dexmedetomidine for prevention of shivering after spinal anesthesia. Journal of anaesthesiology, clinical pharmacology. 2018; 34(3):352.

8. Alipour M, Sharifian A, Dastkhosh A. Effects of magnesium sulfate on prevention of shivering during spinal anesthesia in cesarean section. The Iranian Journal of Obstetrics, Gynecology and Infertility. 2013; 16(79):1-9.

9. JABALAMELI M, SADEGHI A, HIRMANPOUR A. Prevention of shivering during regional anesthesia in cesarean section: Comparison of the two different doses of ketamine and placebo. 2016.

10. Pazoki S, Noroozi A, Shadman AH. Comparison effect of different doses of Ketamine with Pethedine in reducing postoperative shivering after cesarean section. Journal of Arak University of Medical Sciences. 2009; 12(2):9-16.
11. Sahmeddini M, Khademi S, Majidi F. Comparison of effect of Meperidine and Tramadol Treatment on Postoperative Shivering in Elective Cesarean Section. Razi Journal of Medical Sciences. 2008; 14(57):83-90.

12. Safari F, Mottaghi K, Salimi A, Rezaee O, Zahabi Aslee MH, Nashibi M. Evaluation of the effect of dexmedetomidine on the acute hype rdynamic responses, duration of seizure activity and recovery times in patients undergoing ECT. JOURNAL OF IRANIAN SOCIETY ANAESTHESIOLOGY AND INTENSIVE CARE. 2016; 38(32): 62-67.

13. Nasseri K, Ghadami N, Nouri B. Effects of intrathecal dexmedetomidine on shivering after spinal anesthesia for cesarean section: a double-blind randomized clinical trial. Drug design, development and therapy. 2017; 11:1107.

14. Sajedi P, Nazemroaya B, Comparing the effectiveness of antishivering action of meperidine alfentanil, sufentanil, fentanyl and tramadol after general anesthesia. Shiraz E-Medical Journal .2006;7(3):1-6.

15. Zhang J, Zhang $X$, Wang $\mathrm{H}$, Zhou $\mathrm{H}$, Tian $\mathrm{T}$, Wu $\mathrm{A}$. Dexmedetomidine as a neuraxial adjuvant for prevention of perioperative shivering: Meta-analysis of randomized controlled trials. PloS one. 2017; 12(8)

16. Memary E, Shirian S, Sayadi S, Mirkheshti A, Khadempour A. Dexmedetomidie Effect in Femoral Nerve Block on Hemodynamic Parameters during Femoral Shaft Fracture. JOURNAL OF IRANIAN SOCIETY ANAESTHESIOLOGY AND INTENSIVE CARE. 2016; 38(32): 13-20.

17. He L, Xu J-M, Liu S-M, Chen Z-J, Li X, Zhu R. Intrathecal dexmedetomidine alleviates shivering during cesarean delivery under spinal anesthesia. Biological and Pharmaceutical Bulletin. 2017; 40(2):169-73.

18. Usta B, Gozdemir M, Demircioglu RI, Muslu B, Sert H, Yaldiz A. Dexmedetomidine for the prevention of shivering during spinal anesthesia. Clinics. 2011; 66(7):1187-91. 